\title{
Critiques of Axiological Realism and Surrealism
}

Published in Acta Analytica in 2019.

https://doi.org/10.1007/s12136-019-00397-x

pdf:

https://link.springer.com/epdf/10.1007/s12136-019-00397-

$\underline{\mathrm{x}}$ ?author access token=3iiVcyoa5 E5xAIMqpUgEPe4RwlQNchNByi7wbcMAY5eHswb5T

H8Q bpFmNpYqcOeqmTI8GafbAXeJ45jboYLwVnQgNAYc0VWuNhMwMdBKeMsXsfljtQUjDESzLSWQAUzWNe-wzxeK7RkBYFEgXcQ\%3D\%3D

Seungbae Park

Ulsan National Institute of Science and Technology

The Republic of Korea

\begin{abstract}
Lyons's $(2003,2018)$ axiological realism holds that science pursues true theories. I object that despite its name, it is a variant of scientific antirealism, and is susceptible to all the problems with scientific antirealism. Lyons $(2003,2018)$ also advances a variant of surrealism as an alternative to the realist explanation for success. I object that it does not give rise to understanding because it is an ad hoc explanans and because it gives a conditional explanation. Lyons might use axiological realism to account for the success of a theory. I object that some alternative axiological explanations are better than the axiological realist explanation, and that the axiological realist explanation is teleological. Finally, I argue that Putnam's realist position is more elegant than Lyons's.
\end{abstract}

\section{Keywords}

Axiological Realism, Conditional Explanation, Epistemic Realism, Goal of Science

\section{Introduction}

The history of science seems a graveyard of discarded theories, such as the humoral theory and the Ptolemaic theory. These obsolete theories, though successful, were so fundamentally different from their present successors that they were not even approximately true. This gloomy description might be called the graveyard view of the history of science.

Philosophers of science have developed various positions to get around the graveyard view of the history of science. One such philosopher is Timothy Lyons (2003, 2005, 2016, 2017a, 2017b, 2018). He has put forward two original positions: axiological realism and a variant of surrealism. They are unique and more than worthy of consideration. This paper criticizes them with the intent of drawing several philosophical morals for those who aim to develop new philosophical positions to overcome the graveyard view of the history of science.

In Section 2, I unpack axiological realism, comparing it with epistemic realism. I also explicate how axiological realism gets around Larry Laudan's (1981) historical challenge to Hilary Putnam's (1975: 73) famous no-miracles argument. In Section 3, I argue that on close analysis, axiological realism is not a variant of scientific realism but rather a variant of scientific antirealism. In Section 4, I expose the advantages and disadvantages of axiological realism. In Section 5, I accuse Lyons's variant of surrealism of being ad hoc and of giving what I call a conditional explanation. In Section 6, regarding axiological realism, I raise the objection that there are axiological alternatives better than axiological realism, and the 
objection that axiological realism gives a teleological explanation, an explanation that invokes a goal. In Section 7, I argue that Putnam's position is more elegant than Lyons's. In Section 8, I address some possible responses from Lyons. In short, both axiological realism and Lyons's variant of surrealism are problematic views of science.

\section{Axiological Realism vs. Epistemic Realism}

Axiological realism holds that "science seeks true theories" (Lyons, 2005: 167). ${ }^{1}$ By contrast, epistemic realism holds that "we can justifiably believe that our successful scientific theories have achieved (or approximated) this goal" (Lyons, 2005: 167). Lyons continues to formulate axiological realism and epistemic realism these ways in Lyons (2016: 564, 2017a: 1, 2018: 148). The differences between these views of science can be made explicit by answering the following questions: Can we justifiably believe that the oxygen theory of combustion is true? Can we justifiably believe that oxygen exists? Epistemic realists answer "Yes," whereas axiological realists challenge the affirmative answer. Moreover, epistemic realists affirm that a theory, $\mathrm{T}$, is (approximately) true, and that theoretical entities postulated by $\mathrm{T}$ are real, but axiological realists refrain from either of these claims. ${ }^{2}$

What motivated Lyons to develop axiological realism? To answer this question, we must explore the realist meta-hypothesis (Putnam, 1975: 73), Laudan's (1981) objection to it, and Lyons's (2016: Section 2.2.) modus tollens formulation of Laudan's objection. The realist meta-hypothesis asserts that successful scientific theories are (approximately) true. In response, Laudan (1981: 33) provides a list of discarded theories, which were successful, but were not even approximately true. Thus, they are all counterexamples to the realist metahypothesis. Lyons reformulates Laudan's objection as the following modus tollens:

1. If (a) that realist meta-hypothesis were true, then (b) we would have no successful theories that cannot be approximately true. (If we did, each would be a "miracle," which no one of us accepts.)

2. However, (not-b) we do have successful theories that cannot be approximately true: the list (of "miracles").

3. Therefore, (not-a) the realist meta-hypothesis is false. (And the no-miracles argument put forward to justify that meta-hypothesis is unacceptable.) (Lyons, 2016: 566)

To use an analogy, if all crows were black, there would be no blue crows. There are, however, some blue crows. It follows that not all crows are black.

How does axiological realism fend off this modus tollens? The fact that successful theories of the past were not (approximately) true does not negatively affect the assertion that science pursued true theories. Even if science had not obtained true theories, it might have sought them. So axiological realism beautifully overcomes the modus tollens. By contrast, epistemic realism does not. The demise of past theories makes it doubtful that successful scientific theories are warranted. Thus, the graveyard view of the history of science undermines epistemic realism, but not axiological realism. So claims Lyons.

\section{Variants of Scientific Antirealism}

\footnotetext{
${ }^{1}$ In my view, 'teleological' better reflects this view than 'axiological' does. Let me add that Lyons also refers to axiological realism as Socratic realism, Socratic scientific realism, a purely axiological realism, and a nonepistemic, purely axiological scientific realism.

${ }^{2}$ Selectivism is another important position in the literature. It asserts that some parts of a scientific theory are worthy of our belief while others are not (Worrall, 1989; Psillos, 1999; Vickers, 2017; Psillos, 2018).
} 
Many philosophers of science (Papineau, 1996; Chakravartty, 2008; Khalifa, 2010; Devitt, 2011; Ruhmkorff, 2011; Ruttkamp-Bloem, 2013; Wray, 2013; Doppelt, 2014; Mizrahi, 2016; Nickles, 2017) are interested in whether successful theories are true, in whether they are empirically adequate, and in whether the theoretical entities posited by them exist. This section explores what axiological realism says with respect to these issues, and argues that despite its name, axiological realism is a variant of scientific antirealism.

Let me first explicate two key notions: empirical adequacy and success. $\mathrm{T}$ is empirically adequate just in case "what it says about the observable things and events in this world, is true" (van Fraassen, 1980: 12). Thus, all observational consequences of such a theory are true. In contrast, $\mathrm{T}$ is successful if and only if "it passes a battery of standard tests" (Laudan, 1981: 23). Some observational consequences should be true for T to be successful. T must meet other conditions to be successful (Park, 2016a: Section 2).

Axiological realism is less committed than even empiricism to what science claims about observables, as Lyons would admit. Empiricism is defined here as the view that successful theories, such as Newtonian mechanics and Einsteinian mechanics, are empirically adequate. Saying that science seeks true theories does not imply that successful ones are empirically adequate. Suppose science sought true theories in the past, as axiological realism asserts. Successful theories, such as Newtonian mechanics and the phlogiston theory, however, were not empirically adequate (Park, 2001: 78; Lange, 2002: 282; Lyons, 2003: 898). So even if science pursues true theories, successful ones might not be empirically adequate.

Axiological realism is also less committed to what science claims about the world than Ian Hacking's (1983) entity realism. Entity realism claims that we can justifiably believe that theoretical entities exist, insofar as we can manipulate them, although we cannot justifiably attribute any property to them. For example, we can justifiably believe that electrons are real because we can manipulate them, but we cannot justifiably believe that electrons have wave properties. By contrast, axiological realism is not even committed to the view that electrons are real. To say that science sought true theories does not imply that we are justified in believing that phlogiston, ether, and caloric are real. Similarly, to say that science pursues true theories does not imply that we are justified in believing that electrons are real.

There is a noteworthy similarity between axiological realism and entity realism. The term 'realism' is attached to them. It is not clear, however, whether they are variants of scientific realism or antirealism. Neither of them asserts that a theoretical entity has a property that science attributes to it. Nor do they even assert that $\mathrm{T}$ is empirically adequate. We should not be misled by their 'realism' labels. Alan Musgrave makes a beautiful comment about entity realism: "To believe in an entity, while believing nothing else about that entity, is to believe nothing or next to nothing" (2017: 88). In my view, it is questionable whether entity realism and axiological realism can be regarded as forms of realism.

Anjan Chakravartty states that "scientific realism is characterized differently by every author who discusses it, and this presents a challenge to anyone hoping to learn what it is" (2017). I dare say that most of the positions to which 'realism' is attached in the literature do not deserve the label. Juha Saatsi's (2015) minimal realism might as well be called theoretical progressivism (Park, 2017a: 104). James Ladyman's (2014) structural realism might as well be called structuralism. Peter Vickers's (2017) selective realism might as well be called selectivism (Park, 2019a: 94-95).

P. Kyle Stanford (2006) differs from other writers in that he does not use the 'realism' label for his position. He espouses what he calls epistemic instrumentalism, which holds that "even our best scientific theories are simply tools or instruments for making empirical predictions and achieving other practical ends" (Stanford, 2006: 189). He does not call his 
position instrumental realism, although he could on the pretext that his position implies that scientific instruments, such as electron microscopes and Hubble telescopes, are real, or that the entities observed and manipulated by scientific instruments are real. He has chosen the accurate label 'epistemic instrumentalism' over 'instrumental realism' in order not to mislead his readers.

Given that Stanford's position is termed as instrumentalism, entity realism might as well be termed as entitism.' How about axiological realism? Can it be called axiologicalism? This is a thorny question. On the one hand, axiological realism is less committed to science than epistemic instrumentalism. On the other hand, the likes of Bas van Fraassen (1980), Laudan (1984), and Lyons would argue that there is a profound difference between axiological realism and axiological antirealism. So we are in an interesting situation in which we are under pressure to use both 'realism' and 'antirealism' to refer to the same position.

Lyons might observe that axiological antirealism, which he opposes, is built into Stanford's view that "even our best scientific theories are simply tools or instruments for making empirical predictions and achieving other practical ends" (Stanford, 2006: 189). Note that Stanford uses the teleological term 'ends.' Thus, epistemic instrumentalism implies that scientific theories have certain goals.

If I were Stanford, I would reply that we still say that the sun sets in the west, although scientifically speaking, it is incorrect to say so. Similarly, we still say that scientific theories are tools for achieving practical ends, although scientifically speaking, it is incorrect to say so. It is only correct to say that scientific theories perform the function of making predictions and manipulations. If Stanford does not make this move, it is not clear how he can avoid the charge that like axiological realism, epistemic instrumentalism is saddled with the teleological view of the world.

Let me turn to another possible response from axiological realists. They might argue that it is odd to compare axiological realism with entity realism and empiricism, since the latter two are explicitly epistemic, whereas the former is explicitly only axiological.

By comparing axiological realism to entity realism and empiricism, however, I simply intend to make it clear that axiological realism makes less epistemic commitment to science than entity realism and empiricism. Moreover, if it is odd to compare axiological realism to entity realism and empiricism, it would also be odd to compare entity realism and empiricism. After all, entity realism concerns theoretical entities, whereas empiricism concerns observational entities. The point is that a comparison is legitimate, as long as it makes a relevant difference between two targets clear.

Let me now turn to a related possible response from Lyons. Axiological realism is nonepistemic, so it explicitly brackets epistemic commitments. The present paper, however, implies that a low level of epistemic commitment is bad, which requires a justification.

In response to this concern, I argue in the next section that axiological realism is vulnerable to all the problems that plague scientific antirealism.

\section{Advantages and Disadvantages}

Before exposing the disadvantages of axiological realism, I expose the following two advantages of it. First, as seen in Section 2, it gets around the modus tollens. Second, axiological realists can ally with epistemic antirealists in the enterprise to refute positive arguments for epistemic realism, such as the no-miracles argument. After all, they agree that all these arguments are weak.

There are many disadvantages to axiological realism. As a variant of scientific antirealism, it is susceptible to all the criticisms that have been advanced against scientific antirealism in the literature. Those criticisms are fleshed out in Park (2014: 16-19, 2016b: 
120-122, 2017a: 113, 2017b: 31-34, 2017c: 618-623, 2017d: 381-386, 2017e: 572-573, 2018a: 74-78, 2018b: 9-11, 2018c, 2019b: Section 4). I introduce the following two of them here.

First, Park (2017b: 31-34) constructs a pessimistic induction against scientific antirealists. It holds that scientific antirealists "have made philosophical mistakes in the past, so they must be making philosophical mistakes now" (Park, 2017b: 31). For example, van Fraassen's (1980) contextual theory of explanation falls prey to his (1989: 143) argument from a bad lot. Scientific antirealists' past philosophical theories had hidden problems, which were later revealed. It follows that their present theories, whatever they might be, must also have hidden problems which will later be revealed.

How does this pessimistic induction apply to axiological realists? Given that axiological realism is a version of scientific antirealism, the pessimistic induction applies to axiological realists' positive philosophical theories, whatever they might be. Since scientific antirealists have made philosophical mistakes, axiological realists also make philosophical mistakes. Thus, just as scientific antirealists' past philosophical theories had hidden problems, so axiological realists' present philosophical theories have hidden problems.

Lyons might reply that while he accepts the modus tollens against epistemic realism, he does not accept the pessimistic induction against epistemic realism. It is not clear whether accepting the modus tollens, but not the pessimistic induction, amounts to accepting epistemic antirealism. In addition, it is not clear whether the pessimistic induction against epistemic antirealists threatens only epistemic antirealists, or both epistemic realists and antirealists.

As noted in Section 2, however, the modus tollens motivated Lyons to reject epistemic realism and accept axiological realism. Thus, it does not matter whether he accepts the pessimistic induction or not. His position is epistemic antirealism, even though he would insist that his position is axiological realism, a form of realism. In addition, the pessimistic induction against epistemic antirealists does not apply to epistemic realists, given that it appeals to the history of philosophy, in which epistemic antirealists have made philosophical mistakes. I leave to epistemic antirealists the task of constructing a pessimistic induction against epistemic realists.

Second, if scientists espoused the view called epistemic reciprocalism, they would treat axiological realists exactly as axiological realists treat them. Epistemic reciprocalism states that "we ought to treat our epistemic colleagues, as they treat their epistemic agents" (Park, 2017f: 57). Applying this principle, scientists would say that axiological realists seek true philosophical theories, but that we cannot justifiably believe that axiological realists' philosophical theories, whatever they might be, are true.

If axiological realists do not want scientists to take such a negative epistemic attitude toward their philosophical theories, they ought not to take the axiological realist attitude toward scientific theories. A useful way for philosophers to test a philosophical hypothesis of science is to imagine how scientists would respond to it (Park, 2018a: 77, 2018d: 16-17). After all, there "is no reason for thinking that the Golden Rule ranges over moral matters, but not over epistemic matters" (Park, 2018a: 77-78).

Lyons might reply that he does not claim that we can justifiably believe that axiological realism is true, but that instead, he merely treats axiological realism as a tool to aid further inquiry and improvement. To put it differently, he has merely put forward axiological realism for discussion, and he is not an axiological realist. Thus, the pessimistic induction against epistemic antirealists does not refute his position, and he does not mind scientists rejecting axiological realism. Moreover, since he does not embrace axiological realism, scientists are not acting on the Golden Rule when they claim that axiological realists pursue true 
philosophical theories, but that we cannot justifiably believe that axiological realists have obtained true philosophical theories.

Consider, however, that if you advance an original theory, you are a leader with respect to it. If you do not claim that you can justifiably believe it, your colleagues will be less motivated to believe it. Imagine that a witness states in court that she saw the defendant commit murder, and then states that she cannot justifiably believe so. Such a testimony would not lead to the conviction of the defendant. Similarly, if Lyons does not claim that he can justifiably believe that axiological realism is true, his audience will be less motivated to believe it. He contends, for example, "that the pursuit of truth explains and, crucially, that it justifies the pursuit of certain virtues appealed to in theory change" (Lyons, 2005: 172). On this account, scientists pursue simple theories because they pursue true theories. To say, however, that Lyons cannot justifiably believe that axiological realism is true implies that he attempts to explain and justify scientists' pursuit of simple theories with the view that he cannot justifiably believe to be true. It is not clear whether such an explanation and such an argument are worthy of our credence.

In this section, I have critically examined axiological realism. I now turn to Lyons's form of surrealism.

\section{The Surrealist Explanation}

Surrealism states that phenomena occur as if a theory were true (Leplin, 1997: 159). In the surrealist tradition, Lyons proposes that a theory is successful because the "mechanisms postulated by the theory and its auxiliaries would, if actual, bring about all relevant phenomena thus far observed and some yet to be observed at time t" (2003: 900). Lyons (2018: 147) sticks to this proposal, touting it as an alternative to Putnam's proposal. He adds that antirealist alternatives have "suffered recent neglect" (2018: 147).

Contrary to Lyons' claim, antirealist alternatives have not suffered recent neglect. Park (2014) constructs the pessimistic induction against antirealist proposals and then argues that Lyons's variant of surrealism falls prey to it, i.e., that Lyons's proposal has hidden problems because its predecessors turned out to have problems. Park (2016a) has also exposed some intrinsic problems with surrealism in general. One of them is that surrealism attributes the success of $T$ to the world instead of scientists. This paper sets aside these problems and exposes new problems peculiar to Lyons's variant of surrealism.

Lyons's surrealist explanation, quoted above, is murky and complex. It invokes the mechanisms of a theory, the actual mechanisms, the if-clause, a particular time, and an unspecified later time, t. To clarify it, I apply it to the caloric theory and the kinetic theory:

(C) The caloric theory was successful because caloric, if actual, would have produced all the heat phenomena observed up until the end of the $19^{\text {th }}$ century and some other phenomena yet to be observed.

(K) The kinetic theory is successful because molecules, if actual, would produce all the heat phenomena thus far observed and some other phenomena yet to be observed.

(C) and (K) are not committed to the existence of caloric and molecules, respectively, although they invoke caloric and molecules to explain the success of the respective theories. This is a remarkable virtue of Lyons's explanatory scheme from the antirealist point of view. It enables antirealists to explain the success of $T$ without committing to the truth of $T$. Despite this advantage, however, Lyons's surrealist explanation cannot be a serious alternative to the realist explanation because it lacks explanatory power. (C) and (K) do not help you to 
understand, respectively, why the caloric theory was successful and why the kinetic theory is successful. They have the following two intrinsic problems.

First, the explanantia of $(\mathrm{C})$ and $(\mathrm{K})$ are ad hoc. They refer to particular times: the end of the $19^{\text {th }}$ century and the present, respectively. Compare $(\mathrm{C})$ and $(\mathrm{K})$ with scientific explanations, e.g., a material object near the Earth falls down because gravitational force exists between them. This explanans does not refer to any particular time. It does not say that a material object near the Earth falls down because gravitational force has existed between them thus far. Consequently, Lyons owes us an explanation of why (C) and (K) refer to the particular times.

Lyons might answer that $(\mathrm{C})$ refers to the particular time because the caloric theory agreed with all heat phenomena observed until then, but has disagreed with some heat phenomena observed later. Stated differently, $(C)$ refers to the particular time to reflect the fact that no empirical anomaly to the caloric theory had been observed until then, but that some empirical anomalies were observed thereafter. How about $(\mathrm{K})$ ? It refers to the present because the kinetic theory has agreed with all phenomena observed thus far. In other words, $(\mathrm{K})$ refers to the present to reflect the fact that no empirical anomaly to the kinetic theory has yet been observed.

Such a reply, however, amounts to admitting that the explanantia have been concocted for the sole purpose of explaining the explananda, i.e., that the explanantia are gerrymandered for the explananda. To avoid this charge, Lyons should provide independent justifications for referring to the particular times in $(\mathrm{C})$ and $(\mathrm{K})$. He should justify the reference in (C) to the end of the $19^{\text {th }}$ century independently of the fact that the caloric theory then collided with empirical anomalies. He should justify the reference in $(\mathrm{K})$ to the present independently of the fact that the kinetic theory has not yet run into empirical anomalies. Alternatively, he might show that the explanans of (C) explains not only the success of the caloric theory but also another explanandum, and that the explanans of $(\mathrm{K})$ explains not only the success of the kinetic theory but also another explanandum. Otherwise, $(\mathrm{C})$ and $(\mathrm{K})$ have no explanatory powers and fail to give rise to understanding.

Second, there is a more serious flaw with $(\mathrm{C})$ and $(\mathrm{K})$. The explanantia of $(\mathrm{C})$ and $(\mathrm{K})$ are conditional sentences, while the explananda are indicative sentences. Let me distinguish between what I call a conditional explanation and an indicative explanation. A conditional explanation employs only a conditional sentence to explain an indicative sentence. Consider these two examples:

$\left(\mathrm{C}_{1}\right)$ Boiling water is hot because if its constituent molecules moved fast, it would be hot.

$\left(\mathrm{C}_{2}\right)$ Her action is moral because if an action maximizes happiness, it is moral.

In an indicative explanation, by contrast, there is at least one indicative sentence. Let me take the following two examples:

$\left(\mathrm{I}_{1}\right)$ Boiling water is hot because the molecules of boiling water move fast, and if the molecules of an object moved fast, the object would be hot.

$\left(\mathrm{I}_{2}\right)$ Her action is moral because it maximizes happiness if an action maximizes happiness, it is moral.

As these four examples illustrate, an indicative explanation can dispel puzzlement over why an explanandum occurs, whereas a conditional explanation cannot. In general, if an explanandum is an indicative sentence, at least one of the explanantia must be another 
indicative sentence, i.e., a conditional sentence, standing alone, cannot explain an indicative sentence. Lyons's surrealist explanations, $(\mathrm{C})$ and $(\mathrm{K})$, are conditional. For this reason, no sense of understanding can come from them.

Lyons might argue that his explanation can be regarded as indicative, once his explanans is taken to be a description of the relation between $\mathrm{T}$ and the world. On this account, the antecedent of the conditional sentence would be a description of $T$ and the consequent would be a description of the world, and the conditional sentence would be a description of the relation between $\mathrm{T}$ and the world.

This possible response implies that all the conditional sentences are indicative sentences describing the relations between two targets, which the paper might grant for the sake of argument. As Park (2003: 65-66) argues, however, a conceptual problem arises when an intrinsic property is explained in terms of a relational property. It is odd to say, for example, that this swan is white because it is similar to that swan in terms of color. Lyons's surrealist explanation is similar to this odd explanation in that an intrinsic property is explained in terms of a relational property.

Let me turn to another possible response from Lyons. He might contend that I merely stipulate that a conditional sentence alone cannot explain an indicative sentence, that his example shows that this stipulation does not hold, and that he might find other examples.

I welcome anyone to put forward such examples. Let me remind readers that in this paper, I provided two examples of conditional explanations, $\left(\mathrm{C}_{1}\right)$ and $\left(\mathrm{C}_{2}\right)$, neither of which sounds explanatory. Let me add one here: "This object conducts electricity because if an object is silver, it would conduct electricity." Note that there is no connection whatsoever between the explanandum and the explanans, so the explanans does not illuminate why the explanandum occurs.

\section{The Axiological Realist Explanation}

In the previous section, I argued that Lyons's surrealist explanation has problems. Those problems might motivate Lyons to propose an axiological realist explanation. I critically evaluate it in this section.

Regarding entity realism, Musgrave says that if you believe almost nothing, you can explain almost nothing, and thus, since entity realism can explain almost nothing, it is "a hopeless form of realism" (2017: 88). In a similar vein, Park states, "Believe less. Explain less" (2017a: 113). On the basis of these remarks, we can predict that axiological realism, which is even more skeptical about science than entity realism, cannot explain the success of T.

This prediction can be substantiated by considering a successful theory, the Copernican theory, as an example. It truly predicted the retrograde motions of planets. How could it make such predictions? According to the no-miracles argument, it made true predictions because it was (approximately) true, and that it could not have made true predictions, had it not been (approximately) true. So the hypothesis that the Copernican theory was (approximately) true best explains its success.

How would axiological realists explain the success of the Copernican theory? They would suggest that the Copernican theory was successful because science sought true theories. An immediate objection to this suggestion is that there are alternative axiological explanations according to which the Copernican theory was successful because science sought empirically adequate theories or because science sought successful theories. Consider the following three explanantia:

(1) Science sought true theories. 
(2) Science sought empirically adequate theories.

(3) Science sought successful theories.

Which explanans is the best for the success of the Copernican theory? To answer this question, we need to ponder which explanans makes the explanandum most likely. Obviously, (3) does. True theories and empirically adequate theories are not necessarily successful. They need to be supplied, as Lyons (2003: 895) observes, with relevant auxiliaries and technologies to succeed. Thus, $\mathrm{T}$ would be more likely to be successful if science sought successful theories than if it sought true theories or empirically adequate theories. Therefore, if you aim to explain the success of $T$ in the axiological vein, you should choose (3) over (1) or (2) as an explanans for the success of $\mathrm{T}$.

As noted, this criticism against axiological realism echoes Lyons's (2003: 895) criticism against Putnam's realist explanation of the success of T. According to Lyons, T's truth alone cannot account for T's success because "T's truth does not even make it likely that T will succeed empirically" (2003: 895). His idea is that auxiliary assumptions and technologies must be in place for T's truth to make T's success likely. Without auxiliary assumptions and technologies, $\mathrm{T}$, even if true, cannot make true predictions. Moreover, an explanans must make an explanandum likely. Thus, his criticism against Putnam's realist explanation backfires on the axiological realist explanation. He bears the burden of showing that (1) makes the success of T more likely than (2) and (3), and that the pursuit of true theories makes the success of T likely.

There is an even more serious problem with the axiological realist explanation. It is a teleological, and not a mechanical, explanation. A teleological explanation invokes a final cause, whereas a mechanical explanation invokes an efficient cause. Aristotle regarded both teleological and mechanical explanations as acceptable. Modern scientists, such as Newton and Darwin, however, regarded only mechanical explanations as acceptable. Contemporary science follows the tradition of modern scientists. Thus, no teleological explanation appears in current science. Editors of scientific journals today would execute a desk reject on a manuscript containing a teleological explanation. Since contemporary scientists reject teleological explanations, they would also reject the axiological realist explanation.

\section{Lyons's Position vs. Putnam's Position}

Suppose that Lyons's surrealist explanation that we discussed in Section 5 is tenable. Even so, there is a problem with Lyons's position, viz., it is less elegant than Putnam's. Lyons embraces axiological realism on the issue of what epistemic attitude we should take toward successful theories. He, however, embraces surrealism on the issue of how to explain the success of theories. By contrast, Putnam embraces scientific realism on both issues. Lyons's position resembles that of contemporary physicists. Physicists use the general theory of relativity to investigate huge objects and quantum mechanics to investigate tiny objects. They think that there is something wrong with their position and attempt to come up with a more general and fundamental theory that would apply to both very small and very large objects. By parity of reasoning, we should think that there is something wrong with Lyons's position.

It is not clear whether there could be a general and fundamental hypothesis that would unify axiological realism and Lyons's variant of surrealism. Axiological realism invokes a goal, whereas the variant of surrealism does not. Axiological realism is an indicative statement, whereas the variant of surrealism is a conditional statement. The difference between the two views is so huge that I doubt that they share something interesting in common that a general and fundamental hypothesis could make use of. Moreover, since both axiological realism and the variant of surrealism are explanatory failures, as we have seen in 
the previous sections, they are not even candidates for unification.

\section{Possible Responses}

So far, I criticized Lyons's variant of surrealism and axiological realism in the way scientists criticize scientific hypotheses, accusing his surrealist explanation of being a conditional one, axiological realism of invoking a goal, and his position of being inelegant. One might respond that philosophy and science are different enterprises, so it is wrong to impose scientific standards on philosophy.

Such a response, however, is criticized at length by Park (2014: 16-19, 2017c: 620, 2018a: 76, 2018d, 16-17, 2019c: Subsection 3.1). I only add here that Lyons cannot raise it. He maintains that "theories about science should ultimately be treated as part of science and tested empirically against the data to which they pertain, e.g., the history of science" (Lyons, 2005: 171). Given that he says that philosophical theories about science should be tested empirically, he cannot defend axiological realism and his variant of surrealism from my criticisms by saying that philosophy differs from science. He also says, "I consider naturalism to be conducive to and supportive of axiological realism, i.e., the hypothesis that science seeks true theories" (Lyons, 2005: 171). On the contrary, I believe axiological realism and his variant of surrealism are untenable under the naturalistic framework due to the conditional and teleological concerns raised earlier in this paper.

Let me turn to another possible response from Lyons. He might strongly feel tempted to challenge me to defend epistemic realism from the graveyard view of the history of science. After all, in the previous sections, I criticized axiological realism and the variant of surrealism that Lyons developed to get around the graveyard view of the history of science.

The aim of this paper, however, is not to defend scientific realism but rather to criticize Lyons's variant of surrealism and axiological realism. Thus, I shall only briefly introduce the following epistemic and pragmatic justifications for scientific realism that are discussed at length elsewhere.

Let me begin with epistemic justifications for scientific realism. First, "since past theories were false, present theories are true" (Park, 2018e: 330). This argument is an antiinduction for scientific realism. Second, scientific realism can be justified by "scientists' arguments for scientific theories" (Park, 2019d: Section 3). Third, "since the special theory of relativity has been repeatedly reinforced by new methods, it will continue to be reinforced by new methods indefinitely into the future" (Park, 2018f: 54). Fourth, "because evolutionary theory has been supported by its several neighboring theories that were previously unconceived, it will be supported by infinitely many hitherto unconceived neighboring theories" (Park, 2019e: 87). All these arguments differ from the no-miracles argument and are immune to the graveyard view of the history of science.

Let me move onto pragmatic justifications for scientific realism. First, realism is more useful than antirealism in fostering scientists' creativity (Park, 2016b: 120-122). Second, realists can, while antirealists cannot, believe that their own positive theories are true (Park, 2017f: 61). Third, realists have a better chance than antirealists to propagate their positive theories to their epistemic colleagues (Park, 2017f: 62-63). Fourth, realists can, while antirealists cannot, understand phenomena in terms of scientific theories (Park, 2017d: 381386, 2017e: 572-573). Fifth, antirealists' speech acts can be unethical in certain contexts, while realists' speech acts cannot (Park, 2018c: 32-33). Sixth, realists can, while antirealists cannot, invoke scientific theories to explain observables and unobservables. In addition, realists can, while antirealists cannot, use scientific theories to predict unobservables (Park, 2019b: Section 4). Seventh, realists are more likely to receive scholarly awards than antirealists (Park, 2019c: Subsection 3.2). 
I claimed above that epistemic realists can rely on scientists' arguments instead of on the no-miracles argument. Axiological realists might object that in saying that scientists argue for the truth of their theories, I am assuming axiological realism - the idea that scientists seek truth - which I criticized as being teleological and hence unacceptable.

Epistemic realists, however, can reply that scientists construct arguments not because they pursue true theories but rather because certain neurons fire in their brains. In addition, scientists' arguments do not have any goal; they rather perform the function of showing that scientists' theories are true. In short, epistemic realists are not necessarily assuming axiological realism when they appeal to scientists' arguments for the truth of their theories.

\section{Conclusion}

Lyons has developed axiological realism and a variant of surrealism with the view to overcome the modus tollens against the no-miracles argument. This paper has several messages for those who aim to develop original positions. First, a new position, if close to scientific antirealism, should be labeled '--- antirealism' rather than '--- realism.' Second, a new position, if close to scientific antirealism, will be subject to criticisms that have already been raised against scientific antirealism in the literature. Third, a new position, if gerrymandered for an explanandum, will be an ad hoc explanans. Fourth, a new position, if it invokes a goal of science, will yield teleological explanations, which are anathema to naturalists. Fifth, a new position, if objectionable to scientists, might prod scientists to reciprocate by taking a position that is equally objectionable to philosophers of science.

\section{References}

Chakravartty, Anjan (2008). "What You Don't Know can't Hurt You: Realism and the Unconceived”, Philosophical Studies 137 (1): 149-158.

(2017). "Scientific Realism", The Stanford Encyclopedia of Philosophy, Edward N. Zalta (ed.), URL $=<$ https://plato.stanford.edu/archives/sum2017/entries/scientific-realism/>.

Devitt, Michael (2011). “Are Unconceived Alternatives a Problem for Scientific Realism?", Journal for General Philosophy of Science 42 (2): 285-293.

Doppelt, Gerald (2014). “Best Theory Scientific Realism”, European Journal for Philosophy of Science 4 (2): 271-291.

Hacking, Ian (1983). Representing and Intervening: Introductory Topics in the Philosophy of Science. New York: Cambridge University Press.

Khalifa, Kareem (2010). "Default Privilege and Bad Lots: Underconsideration and Explanatory Inference", International Studies in the Philosophy of Science 24 (1): 91-105.

Ladyman, James (2014). "Structural Realism", The Stanford Encyclopedia of Philosophy, Edward N. Zalta (ed.), URL = <http://plato.stanford.edu/archives/spr2014/entries/structuralrealism/>.

Lange, Marc (2002). "Baseball, Pessimistic Inductions and the Turnover Fallacy", Analysis 62 (4): 2881-2885.

Laudan, Larry (1981). “A Confutation of Convergent Realism”, Philosophy of Science 48 (1): 
$19-49$.

(1984). Science and Values California: The Aims of Science and Their Role in Scientific Debate. University of California Press.

Leplin, Jarrett (1997). A Novel Defense of Scientific Realism. New York: Oxford University Press.

Lyons, Timothy (2003). "Explaining the Success of a Scientific Theory", Philosophy of Science 70 (5): 891-901.

--------- (2005). “Toward a Purely Axiological Scientific Realism”, Erkenntnis 63 (2): 167204.

(2016). "Scientific Realism", In Paul Humphreys (ed.), The Oxford Handbook of Philosophy of Science. New York: Oxford University Press: 564-584.

--------- (2017a). "Systematicity Theory Meets Socratic Scientific Realism: The Systematic Quest for Truth”, Synthese. https://doi.org/10.1007/s11229-017-1561-2.

(2017b). "Epistemic Selectivity, Historical Threats, and the Non-Epistemic Tenets of Scientific Realism", Synthese 194 (9): 3203-3219.

(2018). "Four Challenges to Epistemic Scientific Realism", Spontaneous Generations: A Journal for the History and Philosophy of Science 9 (1): 146-150.

Mizrahi, Moti (2016). "The History of Science as a Graveyard of Theories: A Philosophers' Myth”, International Studies in Philosophy of Science 30 (3): 263-278.

Musgrave, Alan (2017). "Strict Empiricism Versus Explanation in Science", In Evandro Agazzi (ed.), Varieties of Scientific Realism: Objectivity and Truth in Science. Switzerland: Springer International Publishing, 71-93.

Nickles, Thomas (2017). "Cognitive Illusions and Nonrealism: Objections and Replies", In Evandro Agazzi (ed.), Varieties of Scientific Realism: Objectivity and Truth in Science. Switzerland: Springer International Publishing, 95-108.

Papineau, David (1996). The Philosophy of Science. Oxford: Oxford University Press.

Park, Seungbae (2001). Scientific Realism vs. Scientific Antirealism. Ph.D. Dissertation, University of Arizona.

-------- (2003). “Ontological Order in Scientific Explanation”, Philosophical Papers 32 (2): $157-170$.

$3-21$.

(2014). “A Pessimistic Induction against Scientific Antirealism”, Organon F 21 (1):

(2016a). “Realism Versus Surrealism”, Foundations of Science 21 (4): 603-614. 
(2016b). “How to Foster Scientists' Creativity”, Creativity Studies 9 (2): 117-126.

(2017a). “Critiques of Minimal Realism”, Problemos 92: 102-114.

16 (1): $23-37$.

(2017b). "Scientific Antirealists Have Set Fire to Their Own Houses", Prolegomena

(2017c). "Why Should We Be Pessimistic about Antirealists and Pessimists?", Foundations of Science 22 (3): 613-625.

--------- (2017d). “Understanding without Justification and Belief?" Principia: An International Journal of Epistemology 21(3): 379-389.

------- (2017e). "Does Scientific Progress Consist in Increasing Knowledge or Understanding?", Journal for General Philosophy of Science 48 (4): 569-579.

64. (2017f). “Defense of Epistemic Reciprocalism", Filosofija. Sociologija 28 (1): 56-

(2018a). “The Pessimistic Induction and the Golden Rule”, Problemos 93: 70-80.

(2018b). "The Problem of Unobserved Anomalies", Filosofija. Sociologija 29 (1):

$4-12$.

(2018c). "Philosophers and Scientists are Social Epistemic Agents", Social Epistemology Review and Reply Collective 7 (6): 31-43.

17: 7-19.

(2018d). "The Grand Pessimistic Induction", Review of Contemporary Philosophy

(2018e). "The Anti-Induction for Scientific Realism", Grazer Philosophische Studien 95 (3): 329-342.

(2018f). "Justifying the Special Theory of Relativity with Unconceived Methods", Axiomathes 28 (1): 53-62.

31 (1): 89-106.

(2019a). “Optimistic Realism over Selectivism”, Kriterion: Journal of Philosophy

(2019b). "Should Scientists Embrace Scientific Realism or Antirealism?", Philosophical Forum 50 (1): 147-158.

(2019c). "The Disastrous Implications of the 'English' View of Rationality in a Social World”, Social Epistemology 33 (1): 88-99.

-------- (2019d). "Localism vs. Individualism for the Scientific Realism Debate", Philosophical Papers. https://doi.org/10.1080/05568641.2018.1500144. 
(2019e). "The Coherence of Evolutionary Theory with Its Neighboring Theories", Acta Biotheoretica 67 (2): 87-102.

Psillos, Stathis (1999). Scientific Realism: How Science Tracks Truth. New York: Routledge. (2018). "Tolstoy's Argument: Realism and the History of Science", Spontaneous Generations: A Journal for the History and Philosophy of Science 9 (1): 68-76.

Putnam, Hilary (1975). Mathematics, Matter and Method (Philosophical Papers, vo. 1), Cambridge: Cambridge University Press.

Ruhmkorff, Samuel (2011). "Some Difficulties for the Problem of Unconceived Alternative", Philosophy of Science 78 (5): 875-886.

Ruttkamp-Bloem, Emma (2013). "Re-enchanting Realism in Debate with Kyle Stanford", Journal for General Philosophy of Science 44 (1): 201-224.

Saatsi, Juha (2015). "Historical Inductions, Old and New", Synthese. DOI:10.1007/s11229015-0855-5.

Stanford, P. Kyle (2006). Exceeding Our Grasp: Science, History, and the Problem of Unconceived Alternatives. Oxford: Oxford University Press.

van Fraassen, Bas (1980). The Scientific Image. Oxford: Oxford University Press.

--------- (1989). Laws and Symmetry. Oxford: Oxford University Press.

Vickers, Peter (2017). "Understanding the Selective Realist Defence against the PMI", Synthese 194 (9): 3221-3232.

Worrall, John (1989). "Structural Realism: The Best of Both Worlds", Dialectica 43: 99-124.

Wray, K. Brad (2013). "The Pessimistic Induction and the Exponential Growth of Science Reassessed", Synthese 190 (18): 4321-4330. 